\title{
Changes in Alveolar Surface Area, Surfactant Protein A, and Saturated Phosphatidylcholine with Postnatal Rat Lung Growth
}

\author{
TAMAKI OHASHI, KENT PINKERTON, MACHIKO IKEGAMI, AND ALAN H. JOBE
}

\begin{abstract}
Department of Pediatrics, Harbor-UCLA Medical Center, UCLA School of Medicine. Torrance, California 90502 [T.O., M.I., A.H.J.J. and Department of Anatomy and Cell Biology, School of Veterinary Medicine. University of California, Davis, Davis, California 95616 [K.P]
\end{abstract}

\begin{abstract}
Most previous studies of the relationship between surfactant and growth have correlated surfactant pool size with lung weight or body weight. We asked how the quantities of the surfactant components surfactant protein A (SP-A) and saturated phosphatidylcholine (Sat PC) recovered by alveolar wash changed with age in relationship to morphologic measurements of alveolar surface area in rats. We also calculated SP-A and Sat PC in total lung per surface area. In groups of three to 14 rats studied on d $1,7,14,21,50$, and 100 of age, the ratio of alveolar surface area to body weight was highest at $d 14$ and lowest at d 100. Alveolar and total lung SP-A and Sat PC were higher relative to body weight and surface area on $d 1$ than at all other ages. Alveolar and total lung SP-A peaked relative to surface area at $\mathbf{d} 21$ and subsequently decreased significantly at $d \mathbf{1 0 0}$. The alveolar Sat PC to surface area ratio also was highest at $\mathrm{d} 21$ and decreased significantly at $d$ 50 and 100 . The SP-A to Sat PC ratio in alveolar washes was not constant across this age range, being highest at $d$ 21 and 50. These measurements demonstrate age-dependent changes in alveolar and total lung SP-A and Sat PC in the rat that continue beyond the newborn period. (Pediatr Res 35: 685-689, 1994)
\end{abstract}

\section{Abbreviations}

SP-A, surfactant protein A

Sat PC, saturated phosphatidylcholine

Lung surfactant is composed of phospholipids and surfactant proteins that function to reduce surface tension at the air-liquid interface of alveoli. Surfactant proteins make up 5-10\% of lung surfactant, and the three nonserum surfactant-associated proteins are called SP-A, SP-B, and SP-C (1). SP-A is the most abundant surfactant protein. This protein is multifunctional with important roles in the surface properties of surfactant as well as the regulation of surfactant component metabolism and host defenses (2-6). Sat PC is the major surface active lipid component of surfactant and makes up approximately $45 \%$ of lung surfactant by weight. Each surfactant protein and surfactant lipid component is thought to be independently regulated in the developing lung (7).

The developmental patterns of SP-A and phospholipids have

Received November 19, 1993; accepted February 17, 1994

Correspondence: Alan H. Jobe, M.D. Ph.D., Harbor-UCLA Research and Education Institute, 1124 West Carson St.. RB-1, Torrance. CA 90502.

Supported in part by grants from the Center for Indoor Air Research (93-09) and the Tobacco-Related Disease Research Program (IRT-442) and by Grant HD11932 from the National Institute of Child Health and Development. been examined in several species. In rabbits, the mRNA and the primary translation product for SP-A increase until just before birth and then decrease somewhat after birth $(8,9)$. Sat PC increases over the last quarter of gestation in both lung tissue and fetal lung fluid of all species that have been evaluated to date. After term birth, total Sat PC continues to increase in the rabbit lung, but the amount of tissue and alveolar Sat PC decreases linearly relative to body weight until about $12 \mathrm{~d}$ of age (10). In contrast, in rats the total contents of SP-A and Sat PC in alveolar washes decrease in absolute amounts transiently during the first week after birth $(11,12)$. The generalization is that tissue and alveolar surfactant pools are larger at term birth than at any other time in an animal's life when the surfactant pools are normalized to body weight, lung weight, lung protein, or type II cell number.

For adult mammals, alveolar Sat PC pool sizes correlate with the log of alveolar surface area (13), linearly with surface area per gram of body weight (14), and linearly with respiratory rate (15). There also is a striking linear correlation of the $\log$ of alveolar surface area to the log of body mass across almost 6 logs of body weight (16). The studies relating surfactant, body weight, and lung morphometry did not report the age of the animals being evaluated. Therefore, we asked whether the relationship between surface area and the principal surfactant lipid Sat PC or SP-A changed with animal age.

\section{MATERIALS AND METHODS}

Animals. Pregnant Sprague-Dawley rats of known gestation (day of breeding being $\mathrm{d} 1$ ) and 50- and 100-d-old rats were purchased (as maximum barrier-maintained viral antibody-free rats) from Zivic-Miller (Zelienople, PA). The rats were killed on d $1,7,14,21,50$, and 100 by intraperitoneal injection of pentobarbital $(100 \mathrm{mg} / \mathrm{kg}$ body weight) followed by transection of the abdominal aorta. Animals from the same breeder were matched for age and weight for the biochemical and morphometric measurements, although the animals were from different litters. Sex was not determined for the 1-d-old and 7-d-old rats used for the biochemical measurements, but only male rats were used for the rest of the study.

Morphometric measurements. A ventral midline neck incision was made and the trachea cannulated. The abdominal cavity was opened, and a midline incision of the diaphragm was made just before instillation of $2 \%$ glutaraldehyde (in cacodylate buffer, pH 7.4, $350 \mathrm{mosmol}$ ) via the trachea at $20 \mathrm{~cm} \mathrm{H}_{2} \mathrm{O}$ pressure. The lungs were allowed to fix in situ $30 \mathrm{~min}$ before removal of the heart and lungs en bloc and storage in fixative.

After a minimum of $24 \mathrm{~h}$ in fixative, the heart and mediastinal tissues were removed and lung volume was determined by fluid displacement (17). Blocks of tissue cranial and caudal to the hilar level of the left lung lobe were dehydrated in increasing concen- 
trations of ethanol and embedded in either glycolmethacrylate or araldite. Glycolmethacrylate-embedded tissues were sectioned with a JB-4 microtome and araldite-embedded tissues with an MT2B ultramicrotome (Sorvall, Wilmington, DE). Glycolmethacrylate sections were $1.5 \mu \mathrm{m}$ thick and araldite sections were $0.5 \mu \mathrm{m}$ thick. All sections were stained with toluidine blue.

A minimum of four sites from the lung parenchyma of each animal were analyzed to determine the alveolar surface fraction and total alveolar surface area available for gas exchange within each age group. Sections from each site were viewed with a Ziess optical microscope with a 21 -line multipurpose test lattice graticule in one of the eyepiece oculars. For each field examined, the number of intercepts the test lines made with the air-tissue interface of alveoli and alveolar ducts were counted. Surface fraction was determined as two times the total number of intercepts divided by the total test line length (adjusted to the magnification used for viewing tissues) (18). Alveolar surface area was determined as the product of surface fraction, parenchymal lung fraction, and fixed lung volume (19). Parenchymal lung fraction in rodents is $0.81(19,20)$.

Alveolar washes. After opening the thorax completely, a tracheostomy was performed and a short, blunt needle (ranging from 21 to 16 gauge, depending on the age of the rat) was inserted. Five aliquots of PBS at $4^{\circ} \mathrm{C}$ were used to visibly fill the lungs. Each aliquot was flushed into and out of the airways three times. The recovered volumes, which were more than $85 \%$ of the injected volumes, were saved as the pooled alveolar wash. After alveolar wash, the lung tissue was removed from the chest and homogenized in PBS using a Tekmar Tissuemizer (Tekmar, Co., Cincinnati, $\mathrm{OH}$ )

Sat PC measurement. Aliquots of alveolar washes and lung homogenates were extracted with chloroform:methanol (2:1, vol/ vol), and Sat PC was recovered from the lipid extracts after osmium tetroxide oxidation according to the methods of Mason et al. (21). Sat PC was quantified by measuring inorganic phosphorus according to Bartlet (22).

$S P-A$ measurement. The amount of SP-A was measured by a double sandwich ELISA using a rabbit anti-rat SP-A polyclonal antibody (23). The lung homogenate was sonicated for $10 \mathrm{~s}$ at $35 \%$ of maximal output using a Sonic Dimembrator (Sonicator, Fisher Scientific, Pittsburgh, PA) and centrifuged for $5 \mathrm{~min}$ at $500 \times g$. The supernatant was used for ELISA. Anti-SP-A IgG fraction $\left(100 \mu \mathrm{g} / \mathrm{mL}\right.$ in $\left.0.1 \mathrm{M} \mathrm{NaHCO}_{3}\right)$ was incubated overnight at room temperature in wells of untreated 96-well microtiterplates (Corning Inc., Corning, NY). The wells were then incubated for $30 \mathrm{~min}$ in PBS containing $1 \%$ (vol/vol) Triton X-100 and $3 \%(\mathrm{wt} / \mathrm{vol}) \mathrm{BSA}(3 \% \mathrm{BSA} / 1 \%$ Triton X-100/PBS). After two washes with $1 \%$ Triton X-100/PBS, $100 \mu \mathrm{L}$ of affinitypurified rat SP-A (a generous gift from Drs. Y. Kuroki and T. Akino, Sapparo, Japan) standard $(0-20 \mathrm{ng}$ in $5 \mathrm{mM}$ Tris- $\mathrm{HCl}$, $\mathrm{pH} 7.0$ ) or various dilutions of samples were added to each well and allowed to incubate at $37^{\circ} \mathrm{C}$ for $90 \mathrm{~min}$. After the wells were washed three times with $3 \%$ BSA/1\% Triton X-100/PBS, 100 $\mu \mathrm{L}$ of biotinylated anti-SP-A IgG fraction were added to each well and incubated at $37^{\circ} \mathrm{C}$ for $90 \mathrm{~min}$. Anti-SP-A IgG was biotinylated using a kit from Amersham (Arlington Heights, IL). After four washes with $1 \%$ Triton X-100/PBS, $100 \mu \mathrm{L}$ of diluted horseradish peroxidase-conjugated streptavidin (Amersham) were added to each well and incubated at $37^{\circ} \mathrm{C}$ for $30 \mathrm{~min}$. After three washes with $1 \%$ Triton X-100/PBS, $100 \mu \mathrm{L}$ of substrate solution $[1 \mathrm{mg} / \mathrm{mL}$ o-phenylenediamine dihydrochloride (Sigma Chemical Co., St. Louis, MO) with $0.002 \%$ (vol/vol) hydrogen peroxide in citrate buffer] were added to each well. The reaction was stopped by the addition of $100 \mu \mathrm{L}$ of $2 \mathrm{M} \mathrm{H}_{2} \mathrm{SO}_{4}$. The absorbance at $490 \mathrm{~nm}$ was recorded with a Microplate Reader (Dynatech Corp., Chantilly, VA). The assay measured SP-A at concentrations between 1 and $20 \mathrm{ng} / \mathrm{mL}$.

Data analysis. Results are presented as mean $\pm \mathrm{SD}$ and analyzed statistically using analysis of variance. Unpaired $t$ tests were used to compare body weight for animals used for the morphometric study and the biochemical measurements. $p<$ 0.05 was accepted as significant.

\section{RESULTS}

The body weights of the animals, alveolar surface area measurements, and surface area to body weight ratios are given in Table 1. There were no significant differences in body weight within each age group for the animals used for the morphologic and the biochemical arms of the study. Alveolar surface area to body weight ratio was highest at $14 \mathrm{~d}$ and lowest at $100 \mathrm{~d}$.

SP-A in either the alveolar wash or the total lung (sum of alveolar wash and lung tissue) did not increase significantly until $21 \mathrm{~d}$ of age (Fig. 1). SP-A increased in the total lung until d 100, but the alveolar wash recoveries of SP-A decreased between 50 and $100 \mathrm{~d}$. The pattern of increase was different for Sat PC in that Sat PC decreased in the alveolar wash between $\mathrm{d} 1$ and 7 and then increased progressively at all older ages. In the total lung, Sat PC increased at each age.

Both SP-A and Sat PC per body weight were higher in alveolar washes and total lung on $\mathrm{d} 1$ than at any other age (Fig. 2). Alveolar SP-A per body weight was similar on d 7, 14, and 50, but the ratio increased significantly on $\mathrm{d} 21$ and decreased relative to all other ages on d 100. Total lung SP-A per body weight had a profile similar to that of alveolar wash, with the ratio being higher on $\mathrm{d} 21$ than at any age other than $\mathrm{d} 1$. The alveolar Sat PC to body weight ratio did not change significantly on d 7,14 , or 21 , but it then decreased on $\mathrm{d} 50$ and 100 . There was a progressive age-dependent decrease in the Sat PC to body weight ratio for the total lung.

The ratio of SP-A to Sat PC was constant on d 1, 7, and 14 (Fig. 3). This ratio then increased about 2 -fold on $\mathrm{d} 21$ and 50 , and again decreased by $\mathrm{d} 100$. There was no consistent relationship between SP-A and Sat PC in alveolar surfactant versus age.

The normalization of SP-A to alveolar surface area yields a complex relationship (Fig. 4). The ratio decreases 7 -fold between $\mathrm{d} 1$ and 7 and subsequently increases significantly on $\mathrm{d} 21$. The ratio then increases progressively on $\mathrm{d} 50$ and 100 . This same general pattern occurs in the total lung. The normalization of Sat PC to surface area for alveolar Sat PC yields age-dependent ratio changes that are qualitatively similar to but of a smaller magnitude than those noted for SP-A. In contrast, the Sat PC to surface area ratios calculated for the total lung decrease progressively with age.

\section{DISCUSSION}

We correlated Sat PC and SP-A with surface area because this measurement should be the most relevant in terms of the biophysical function of surfactant. Lung surface area correlates very closely with body weight (16), and surfactant lipid pools previously have been correlated linearly with surface area (14). Our findings demonstrate that the relationships between the surfactant components SP-A and Sat PC and body weight or surface area vary significantly with animal age. Septation of the alveolus occurs in rats mainly between the 4th and 14th postnatal day; thinning of the alveolar wall accelerates in the third postnatal week and is completed by the end of that week $(24,25)$. Massaro et al. (26) measured surface area to body weight ratios for Sprague-Dawley rats from another supplier at 1, 3,6, 10, and 14 $\mathrm{d}$ and in young adult rats with a mean body weight of $117 \mathrm{~g}$. They found a maximum ratio of $27-30 \mathrm{~cm}^{2} / \mathrm{g}$ in the $10-\mathrm{d}$-old, 14-d-old, and young adult rats. The highest surface area to body weight ratio that we found was approximately $24 \mathrm{~cm}^{2} / \mathrm{g}$ at 7 and $14 \mathrm{~d}$, which was consistent with the findings of Massaro et al. (26). However, the ratio decreased almost 3-fold by $100 \mathrm{~d}$ of age. With aging in the rat, the ratio of surface area to body weight decreases further as alveoli become larger $(19,20)$. Although alveolar surface area probably reaches maximum values by $5 \mathrm{mo}$ of age, body weight continues to increase throughout life in 
Table 1. Description of animals (values as mean $\pm S D)^{*}$

\begin{tabular}{|c|c|c|c|c|c|c|}
\hline \multirow[b]{2}{*}{ Age (d) } & \multicolumn{2}{|c|}{$\begin{array}{l}\text { Animals for Sat PC and } \\
\text { SP-A measurements }\end{array}$} & \multicolumn{4}{|c|}{ Animals for surface area measurements } \\
\hline & $n$ & $\mathrm{BW}(\mathrm{g})$ & $n$ & $\mathrm{BW}(\mathrm{g})$ & $\mathrm{SA}\left(\mathrm{cm}^{2}\right)$ & $\mathrm{SA} / \mathrm{BW}\left(\mathrm{cm}^{2} / \mathrm{g}\right)$ \\
\hline 7 & 13 & $19.2 \pm 1.4$ & 4 & $17.8 \pm 1.2$ & $408 \pm 43$ & $22.9 \pm 1.9 \dagger$ \\
\hline 14 & 10 & $34.1 \pm 2.8$ & 4 & $31.2 \pm 4.8$ & $748 \pm 50$ & $24.3 \pm 2.6$ \\
\hline 21 & 9 & $61.5 \pm 3.3$ & 3 & $69.3 \pm 4.5$ & $1279 \pm 94$ & $18.4 \pm 0.7 \dagger$ \\
\hline 100 & 5 & $570.8 \pm 24.8$ & 5 & $586.2 \pm 41.3$ & $5204 \pm 914$ & $8.9 \pm 1.5 \dagger$ \\
\hline
\end{tabular}

* BW, body weight; SA, surface area.

$\dagger p<0.05$ for $\mathrm{SA} / \mathrm{BW}$ ratio compared with the previous age.
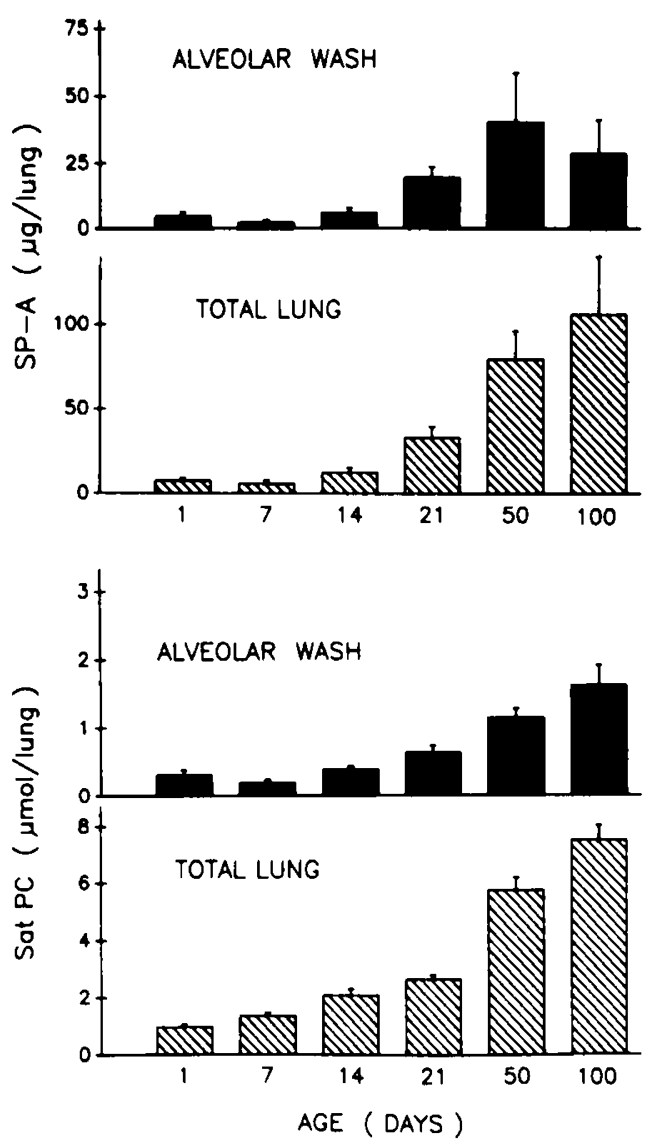

Fig. 1. Amounts of SP-A and Sat PC in alveolar washes and total lungs (sum of alveolar washes and lung tissue) at different ages. SP-A in alveolar washes differed by age: $1 \mathrm{~d}, 7 \mathrm{~d}, 14 \mathrm{~d}<21 \mathrm{~d}<100 \mathrm{~d}<50 \mathrm{~d}, p$ $<0.05$. Total lung SP-A recoveries increased with age: $1 \mathrm{~d}, 7 \mathrm{~d}, 14 \mathrm{~d}<$ $21 \mathrm{~d}<50 \mathrm{~d}<100 \mathrm{~d}, p<0.01$. Alveolar Sat PC decreased on $\mathrm{d} 7$ relative to $\mathrm{d} 1(p<0.05)$ and subsequently increased at each age $(p<0.01)$. Total lung Sat PC increased at each age $(p<0.01)$.

Sprague-Dawley rats. Measurements of surface area may vary depending on the conditions of fixation and examination. For these studies, fixation technique and the surface area measurements by light microscopy were carefully controlled to permit comparisons across age.

Estimates of alveolar SP-A and Sat PC also are subject to variability because the lavage procedure may stimulate surfactant secretion and may be more or less complete. We used a standardized technique known to recover most of the alveolar surfactant pool (27). We also were careful to recover most of the lavage fluid. Such a lavage procedure is a reasonable way to collect material for the measurement of surfactant components at different ages.

A number of investigators have described the changes in
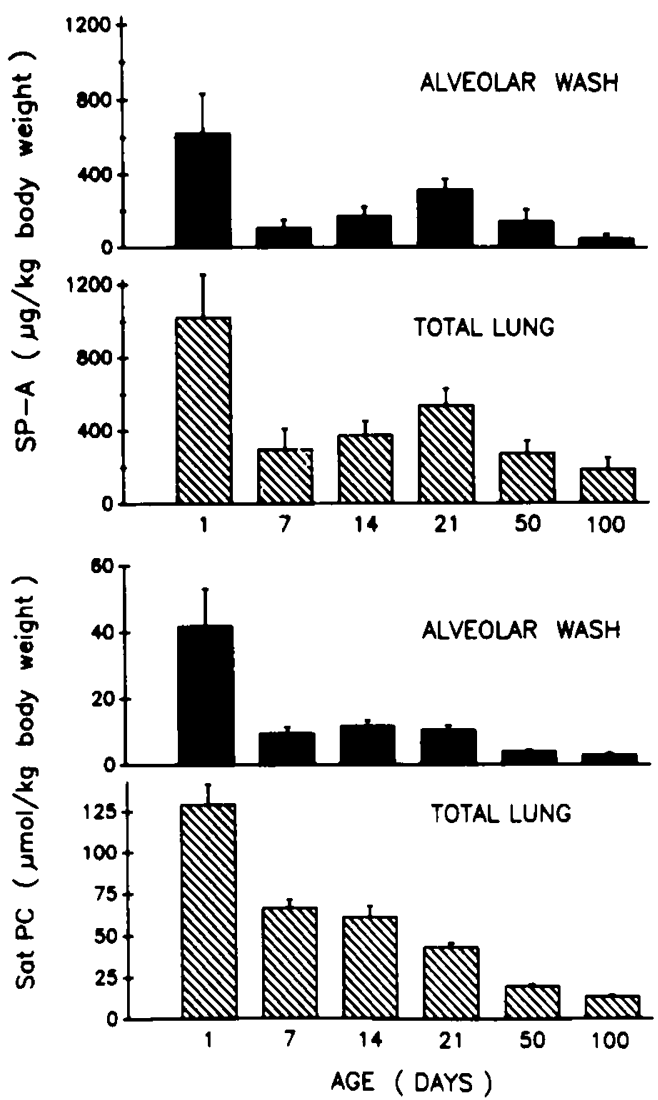

Fig. 2. Alveolar wash and total lung SP-A to body weight and Sat PC to body weight ratios. All ratios on $\mathrm{d} 1$ were higher than at any other age $(p<0.01)$. Significant changes in alveolar SP-A were $21 \mathrm{~d}>7 \mathrm{~d}, 14 \mathrm{~d}$. $50 \mathrm{~d}>100 \mathrm{~d}(p<0.05)$. In the total lung, $21 \mathrm{~d}>$ all other ages except $1 \mathrm{~d}$ and $100 \mathrm{~d}<7 \mathrm{~d}, 14 \mathrm{~d}$, and $21 \mathrm{~d}(p<0.05)$. The Sat PC to body weight ratio in the alveolar wash changed as follows: $7 \mathrm{~d}, 14 \mathrm{~d}, 21 \mathrm{~d}>$ $50 \mathrm{~d}$ or $100 \mathrm{~d}(p<0.01)$. The total lung Sat PC to body weight ratio fell at each age $(p<0.05)$.

surfactant phospholipid and SP-A from late gestation through the immediate newborn period in a variety of species. In the rat, there are increases in alveolar surfactant not associated with a loss of lamellar bodies from type II cells that imply complex relationships between intracellular and extracellular pools (12, 28,29 ). Stevens et al. (30) demonstrated that, at birth, secretion and surfactant phospholipid reuptake occurred simultaneously, with the net effect being a large increase in the alveolar pool on the first day of life. In the rabbit, the alveolar surfactant pool/ body weight ratio then decreases to that of the 1- to $2-\mathrm{kg}$ adult animal by about 2 wk of life (10). In the rat, Randell $e t$ al. (12) and Schellhase et al. (11) noted that total Sat PC and SP-A decreased until about $7 \mathrm{~d}$ of life; this was qualitatively confirmed by our measurements. Whereas alveolar and total lung SP-A 


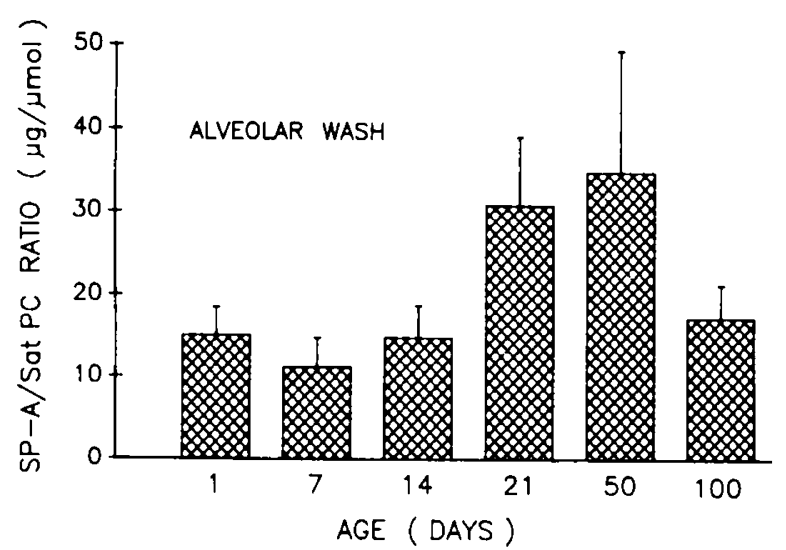

Fig. 3. Ratios of SP-A to Sat PC in alveolar washes. The ratios were higher on $\mathrm{d} 21$ and 50 than at the other ages $(p<0.01)$.
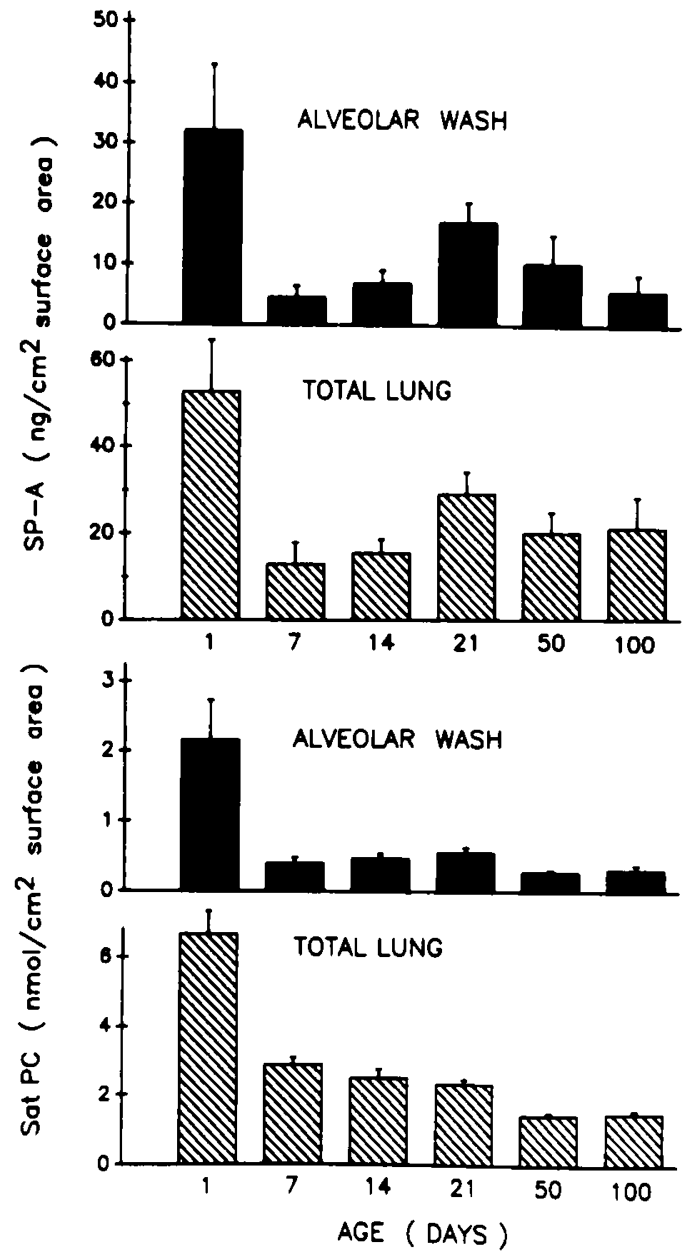

Fig. 4. Alveolar wash and total lung SP-A to surface area and Sat PC to surface area ratios. All ratios on $d 1$ were higher than at any other age $(p<0.01)$. The other alveolar SP-A to surface area ratio differences are $21 \mathrm{~d}>50 \mathrm{~d}>7 \mathrm{~d}, 14 \mathrm{~d}, 100 \mathrm{~d}(p<0.05)$. The Sat PC to surface area ratios for alveolar washes differ as follows: $50 \mathrm{~d}, 100 \mathrm{~d}<7 \mathrm{~d}, 14 \mathrm{~d}<21$ d $(p<0.05)$. The ratios for the total lung decrease with age significantly until $50 \mathrm{~d}(p<0.05)$ and then do not change.

pools increased from $\mathrm{d} 7$ to $\mathrm{d} 50$, there was a decrease in alveolar SP-A on d 100 of age. This absolute decrease in alveolar SP-A is amplified when expressed relative to body weight or surface area, which both increased with age. This decrease in SP-A is an unexpected finding that could have implications for the animals. SP-A is a multifunctional protein that seems to interact with pathogens (5) and macrophages (31) to augment host defense.
We speculate that low alveolar surfactant pools in old age could contribute to the increased problem with lung infections. In contrast to alveolar SP-A, total lung SP-A pools were relatively constant after $d 1$ of life.

The changes in alveolar Sat PC pools were qualitatively similar to those measured for SP-A, with Sat PC per surface area increasing until d 21 and then being lower on d 50 and 100 than at other ages. Total lung Sat PC decreased progressively with age. At d 7, alveolar Sat PC was 14\% of the total lung pool, and this percentage increased to $22 \%$ at $100 \mathrm{~d}$. Although Sat PC is the major phospholipid component of lamellar bodies and alveolar surfactant, it is not only in surfactant metabolic pathways in the lung and thus is not a specific marker for surfactant or type II cells (32). Similarly, SP-A is in both type II cells and Clara cells and may have different functions in each cell type (33). Animal age must be considered a significant variable when the relationships between surfactant and birth weight or surface area are compared.

Acknowledgments. The authors thank Christina C. Chang, Adam Eliott, and Scott Wong for technical assistance.

\section{REFERENCES}

1. Possmayer F 1990 The role of surfactant-associated proteins. Am Rev Respir Dis 142:749-752

2. Schurch S, Possmayer F, Cheng S, Cockshutt AM 1992 Pulmonary SP-A enhances adsorption and appears to induce surface sorting of lipid extract surfactant. Am J Physiol 263:L210-L218

3. Rice WR, Ross GF, Singleton FM, Dingle S, Whitsett JA 1987 Surfactantassociated protein inhibits phospholipid secretion from type Il cells. J Appl Physiol 63:692-698

4. Wright JR, Wager RE. Hawgood S, Dobbs L. Clements JA 1986 Surfactant apoprotein $\mathrm{M}_{\mathrm{r}}=26.000-36,000$ enhances uptake of liposomes by type II cells. J Biol Chem 262:2888-2894

5. van Iwaarden JF, van Strijp JAG, Ebskamp MJM, Welmers AC, Verhoef J, van Golde LMG 1991 Surfactant protein $A$ is opsonin in phagocytosis of herpes simplex virus type 1 by rat alveolar macrophages. Am J Physiol 261:L204-L209

6. Richman PS, Batcher S, Catanzaro A 1990 Pulmonary surfactant suppresses the immune lung injury response to inhaled antigen in guinea pigs. J Lab Clin Med 116:18-26

7. Weaver TE. Whitsett JA 1991 Function and regulation of expression of pulmonary surfactant associated proteins. Biochem J 273:249-264

8. Connelly IN, Hammond GL. Harding PGR. Possmayer F 1991 Levels of surfactant-associated protein messenger ribonucleic acids in rabbit lung during perinatal development and after hormonal treatment. Endocrinology 129:2583-2591

9. Durham PL, Nanthakumar EJ, Snyder JM 1992 Developmental regulation of surfactant-associated proteins in rabbit fetal lung in vivo. Exp Lung Res 18:775-793

10. Jobe AH, Ikegami M, Jacobs H 1981 Changes in the amount of lung and airway phosphatidylcholine in 0.5-12.5-day-old rabbits. Biochim Biophys Acta 66:182-187

11. Schellhase DE, Emrie PA. Fisher JH, Shanon JM 1989 Ontogeny of surfactant apoproteins in the rat. Pediatr Res 26:167-174

12. Randell SH, Silbajoris R. Young SL 1991 Ontogeny of rat lung type II cells correlated with surfactant lipid and surfactant apoprotein expression. Am J Physiol 260:L562-L570

13. Gail DB. Steinkamp H. Massaro D 1978 Interspecies variation in lung lavage and tissue saturated phosphatidylcholine. Respir Physiol 33:289-297

14. Clements JA 1971 Comparative lipid chemistry of lungs. Arch Intern Med 127:387-389

15. Pre J, Perret G. Bladier D 1983 Lecithin content estimate of human alveolar lining layer: comparison with mouse, rat and rabbit. Comp Biochem Physiol 76A:393-395

16. Weibel ER 1987 Scaling of structural and functional variables in the respiratory system. Annu Rev Physiol 49:147-159

17. Scherle $W 1970 \mathrm{~A}$ simple method for volumetry of organs in quantitative stereology. Mikeroskopie 26:57-60

18. Weibel ER 1979 Stereological Methods, Vol 1. Academic Press, New York

19. Pinkerton KE, Barry BE, O'Neil JJ, Raub JA, Pratt PC, Crapo JD 1982 Morphologic changes in the lung during the lifespan of Fischer 344 rats. Am J Anat 164:155-174

20. Burri PH, Doaly J, Weibel ER 1974 The postnatal growth of the rat lung. I. Morphometry. Anat Rec 178:711-730

21. Mason RJ, Nellenbogen J, Clements JA 1976 Isolation of disaturated phosphatidylcholine with osmium tetroxide. J Lipid Res 17:281-284

22. Bartlett GR Phosphorus assay in column chromatography. J Biol Chem 234:466-468

23. Kuroki Y, Takahashi H, Fukada Y, Mikawa M, Inagawa A, Fujimoto S. Akino T 1985 Two-site "simultaneous" immunoassay with monoclonal antibodies 
for the determination of surfactant apoproteins in human amniotic fluid. Pediatr Res 19:1017-1020

24. Burri PH 1974 The postnatal growth of the rat lung. Anat Rec 180:77-98

25. Randell SH, Mercer RR, Young SL 1989 Postnatal growth of pulmonary acini and alveoli in normal and oxygen-exposed rats studied by serial section reconstructions. Am J Anat 186:55-68

26. Massaro D, Teich N, Maxwell S, Massaro GD, Whitney P 1985 Postnatal development of alveoli. J Clin Invest 76:1297-1305

27. Jacobs H, Jobe AH, Ikegami M, Jones S 1982 Surfactant phosphatidylcholine source, fluxes, and turnover times in 3-day-old, 10-day-old, and adult rabbits. Jource, fluxes, and turnover tim

28. Faridy EE, Thliveris JA, Morris GS 1981 Relationship between lung intra- and extracellular DSPC in fetal and neonatal rats. Respir Physiol 45:55-65
29. Spain CL, Silbajoris R, Young SL 1987 Alterations of surfactant pools in fetal and newborn rat lungs. Pediatr Res 21:5-9

30. Stevens PA, Wright JR, Clements JA 1987 Changes in quantity, composition, and surface activity of alveolar surfactant at birth. J Appl Physiol 63:10491057

31. van Iwaarden F, Welmers B, Verhoef J, Haagsman HP, van Golde LMG 1990 Pulmonary surfactant protein $A$ enhances the host-defense mechanism of rat alveolar macrophages. Am J Respir Cell Mol Biol 2:91-98

32. Wright JR 1990 Clearance and recycling of pulmonary surfactant. Am J Physiol 259:L1-L12

33. Phelps DS, Floros $\mathrm{J} 1988$ Localization of surfactant protein synthesis in human lung by in situ hybridization. Am Rev Respir Dis 137:939-942 